\title{
SISTEMAS ADESIVOS: EVOLUÇÃO E PERSPECTIVAS - REVISÃO DE LITERATURA
}

\section{ADHESIVE SYSTEMS: EVOLUTION AND PERSPECTIVES - LITERATURE REVIEW}

\author{
Luciano Bonatelli Bispo \\ Autor para correspondência: Luciano Bonatelli Bispo - Ibbispo@ig.com.br \\ Doutor em Dentística pela FOUSP \\ Especialista em Implantodontia SENAC
}

\section{R E S U M O}

\begin{abstract}
Introdução: A odontologia adesiva desenvolveu materiais e técnicas capazes de preservar o tecido dentário através da união do substrato com sistemas resinosos adesivos. Modernamente os componentes resinosos são utilizados em restaurações adesivas diretas, na cimentação de bráquetes ortodônticos, na cimentação de restaurações indiretas, na obturação de canais radiculares, no selamento de regiões de má coalescência do esmalte como cicatrículas e fissuras, entre outros. Objetivos: $O$ objetivo desse estudo foi fazer uma revisão sobre a evolução dos sistemas adesivos e discutir os principais esforços da atualidade em aprimorá-los no sentido de minimizar seus inconvenientes. Métodos: Seleção de artigos através das bases eletrônicas LILACS e PubMed/ MEDLINE usando os termos de indexação: adesivos dentinários, adesivos e hidrólise entre os anos de 1999 e 2016. Resultados: Os sistemas adesivos têm sido motivo de estudos no sentido de preservar a interface existente entre a resina composta e o esmalte e a dentina. Essa união apresenta problemas como: degradação hidrolítica, separação de fases entre os componentes hidrofílicos e hidrofóbicos, falta de homogeneidade na formação da camada híbrida, exposição de fibrilas colágenas não completamente envolvidas pelos monômeros a serem polimerizados, lixiviação dos monômeros, diferenças no gradiente de concentração osmótico, dificuldade de maior intimidade entre materiais orgânicos e inorgânicos, interação ou remoção da smear layer e presença de bactérias quiescentes nessa interface adesiva. Os maiores inconvenientes são: nanoinfiltração, com invasão bacteriana e cáries secundárias. Conclusões: Conhecer os avanços nos sistemas adesivos e empregá-los corretamente é fundamental para um prognóstico favorável da qualidade das restaurações estéticas adesivas.
\end{abstract}

Palavras-chave: adesivos dentinários, adesivos, hidrólise 
Introduction: The adhesive dentistry developed materials and techniques capable to preserve the dental tissues through the union of substrate with adhesive resinous systems. Modernly the resinous components are used in direct adhesive restorations, in orthodontic brackets' luting, in indirect restorations' luting, in canal root filling, in sealing areas of bad coalescence like pit and fissures, among others. Objective: The aim of this study was to do a review about the evolution of adhesive systems and to discuss the main efforts of the present time in perfecting them in the sense of minimizing their inconveniences. Methods: Selection of papers through electronic bases LILACS and PubMed/ MEDLINE using indexing terms like: dentinbonding agents, adhesives and hydrolysis among the years of 1999 and 2016. Results: The adhesive systems have been reason studies in the sense of preserving the existent interface between the composed resin and enamel and dentine. That union presents problems as: hydrolytic degradation, separation of phases among hydrophilic and hydrophobic components, homogeneity lack in the formation of hybrid layer, exhibition of collagenous fibrils no completely involved by the monomers to be polymerized, leaching monomers, differences in osmotic concentration gradient, difficulty of larger intimacy among organic and inorganic materials, interaction or removal of the smear layer and presence of quiescent bacterias in adhesive interface. The largest inconveniences are: nanoleakage, with bacterial invasion and secondary decays. Conclusions: To know the progresses in the dentin-bonding agents and how to use them correctly is fundamental for a favorable prognostic of the quality of adhesive aesthetic restorations.

Keywords: dentin-bonding agents, adhesives, hydrolysis 


\section{INTRODUÇÃO}

A adesão é proporcionada pela interação entre a dentina com sua desmineralização, pelo ácido aplicado, e exposição da trama colágena intertubular, em sua maioria, com consequente infiltração e permeação dos monômeros hidrofílicos pelo primer e posterior polimerização dos monômeros hidrofóbicos contidos no adesivo (bond), formando uma camada ácido-resistente pelo embricamento mecânico, procurando-se o selamento dessa interface entre $\circ$ adesivo/dentina e a posterior colocação da resina composta, minimizando a penetração de bactérias, suas endotoxinas, fluidos e eletrólitos'.

Contudo, tal interface é uma membrana permeável que pode sofrer nanoinfiltração e hidrólise ${ }^{2}$. A hidrólise é um processo químico em que há a quebra de ligações covalentes no polímero por adição de água às ligações éster, resultando na perda de substância, contribuindo para a redução da tensão das ligações adesivas com o decorrer do tempo ${ }^{3}$.

A infiltração de água em escala nanométrica (nanoinfiltração) na base da camada híbrida (dita ácido resistente) pode interferir na polimerização do sistema adesivo, permitindo que monômeros residuais susceptíveis à lixiviação se desprendam, - que pode contribuir com as expressões clínicas de sensibilidade pós-operatória, acúmulo de placa bacteriana e possível estabelecimento de lesão cariosa secundária².

Avanços nos materiais e técnicas têm sido propostos para impedir ou minimizar tal degradação hidrolítica. Assim, alterações nos monômeros ${ }^{3}$, nos antimicrobianos $^{4}$, nos dessensibilizantes ${ }^{5}$ e nos solventes $^{6}$ dos sistemas adesivos são tentativas promissoras que trazem a perspectiva de uma adesão com maior longevidade na prática clínica.

O objetivo dessa revisão é elucidar os avanços nos sistemas adesivos, bem como as perspectivas futuras de estudos atuais na área para melhora da qualidade da união adesiva.
MÉTODOS

A seleção de artigos foi realizada por busca eletrônica em duas bases de dados: LILACS e PubMed/MEDLINE, com os termos de indexação: adesivos dentinários (dentin-bonding agents), adesivos (adhesives) e hidrólise (hydrolysis). Foram considerados elegíveis artigos publicados entre os anos de 1999 a 2016, disponíveis on line, preferencialmente em língua inglesa, que mantivessem relação com $\circ$ tema dessa revisão. Maior ênfase foi dada aos artigos mais recentes, com destacadas inovações técnicas baseadas em evidências científicas.

\section{REVISÃO DE LITERATURA}

Buonocore $^{7}$ em 1955, considerado o pai da odontologia adesiva e autor mais citado na literatura pertinente, propôs o condicionamento ácido do esmalte dentário. Criou-se um padrão microrretentivo na estrutura adamantina. Houve alteração do padrão topográfico-morfológicomicroscópico superficial que favoreceu a interação com a resina acrílica, material disponível à época, aumentando a superfície de contato. Isso favoreceu a criação de interdigitações denominadas tags, que aumentaram $\circ$ embricamento micromecânico e melhoraram a retenção de tais restaurações em esmalte. É mais fácil e previsível promover a adesão em esmalte do que em dentina, devido ao fato do primeiro ser mais inorgânico e o segundo apresentar maior composição orgânica, principalmente colágeno do Tipo $1^{8}$. Os adesivos de Primeira Geração eram os chamados "primers cavitários", caracterizados por apresentarem baixa força de adesão. Os adesivos de Segunda Geração recomendavam o condicionamento do esmalte dentário o que ocasionou uma melhora na força de união. $O$ condicionamento ácido da dentina começou a ser executado nos adesivos de Terceira Geração para remoção parcial e modificação da smear layer. Na Quarta Geração a técnica "Total Etch" foi adotada, com primer e bond em fracos separados onde começou a ser observada a camada híbrida e os tags resinosos dentro dos túbulos dentinários. 
Na Quinta Geração houve a simplificação do procedimento adesivo convencional, com primer e bond no mesmo frasco. As Sexta e Sétima Gerações são caracterizadas pelo emprego dos sistemas autocondicionantes com primer autocondicinante e bond separados ou em único frasco. Há os que defendem uma Oitava Geração para os chamados adesivos universais (primer, bond, primer ácido e silano no mesmo frasco) ${ }^{9}$, que empregam o MDP (10-metacriloiloxidecil dihidrogênio fosfato), porém isso ainda é motivo de discórdia entre autores ${ }^{10} \mathrm{e} a$ grande maioria não utiliza mais a classificação por gerações para os sistemas adesivos e sim quanto ao número de etapas que envolvem a sua utilização. Assim temos: Convencionais- três passos (ácido + primer + adesivo em frascos separados) e dois passos (ácido + primer e adesivo em mesmo frasco); e Autocondicionantes- dois passos (ácido e primer em mesmo frasco + adesivo) e um passo (ácido, primer e adesivo, todos em mesmo frasco). As três etapas são fundamentais. A primeira é a desmineralização da dentina com ácido e exposição da rede de fibrilas colágenas, a segunda diz respeito à infiltração dos monômeros hidrofílicos contidos no primer e a terceira é a permeação com monômeros resinosos hidrofóbicos constantes no Bond ${ }^{6}$.

\section{DISCUSSÃO}

\section{DEGRADAÇÃO HIDROLÍTICA (HIDRÓLISE)}

$O$ principal mecanismo de união entre a dentina humana e as resinas compostas é determinado pela hibridização da porção superficial da dentina desmineralizada com monômeros resinosos de um sistema adesivo aplicado previamente à inserção da resina restauradora. Pesquisas confirmam a eficiência desta camada em produzir altos valores de força de união, contudo, vários estudos têm mostrado sua ineficiência em manter a estabilidade da união ao longo do tempo ${ }^{11}$. Todos os componentes da união, em especial adesivo e dentina desmineralizada, são susceptíveis à degradação, principalmente devido à ação da água ${ }^{12}$.

A literatura mostra que todos os adesivos, com exceção dos autocondicionantes, são incapazes de penetrar em toda a área desmineralizada ${ }^{13}$, deixando zonas de colágeno desprotegidas que podem ser infiltradas pela água (nanoinfiltração) 2,14 , iniciandose a degradação, tanto do componente resinoso quanto da porção orgânica dentinária. Além disso, mesmo ocorrendo perfeita impregnação das fibrilas de colágeno, a interface ainda estará susceptível à deterioração, devido à natureza hidrofílica das resinas adesivas. Sano et al. $^{2}$ mostraram em um estudo clássico "In vivo" que, apesar da união entre a dentina e um adesivo autocondicionante ter se apresentado estável no período de um ano em relação à resistência à microtração, o aumento da porosidade da camada híbrida foi observado. Estes autores discutem que esta porosidade aumentada pode estar relacionada à remoção do material resinoso pela água. Estes aspectos parecem ser ainda mais pronunciados nos sistemas em que primer e adesivo estão juntos num mesmo frasco.

Os sistemas de frasco único surgiram com o objetivo de simplificar a técnica adesiva, contudo, alguns estudos têm demonstrado maior grau de nanoifiltração nas interfaces formadas entre estes adesivos e a dentina $^{4,15}$, bem como maior susceptibilidade das mesmas à degradação ${ }^{16}$, em relação aos sistemas de dois frascos. Já foi demonstrado ${ }^{1}$, por meio do teste de microtração, que os sistemas de frasco único testados foram inferiores aos demais, mesmo em períodos curtos de 1 e 6 meses de armazenamento em água.

Verificou-se que a distribuição dos monômeros resinosos de quatro marcas comerciais de adesivos de frasco único na camada híbrida é heterogênea e isso poderia afetar sua performance de polimerização, comprometendo a resistência e a durabilidade da união ${ }^{13}$. Ainda, a difusão destes monômeros é dependente do tempo, de forma que a aplicação sequencial de um primer e depois do adesivo poderia oferecer mais tempo para que este processo ocorresse de forma adequada ${ }^{13}$.

Assim, a incorporação de monômeros hidrofílicos e hidrofóbicos num mesmo frasco complica o processo de difusão, aumentando a separação monomérica dentro da camada híbrida e contribuindo para a maior sensibilidade de técnica destes adesivos ${ }^{17}$.

Tay ef al. ${ }^{18}$ demonstraram que os adesivos de frasco único podem funcionar como membranas semi-permeáveis. Os autores especulam que 
a passagem de água através da camada de adesivo polimerizado pode ocorrer na presença de concentrações aumentadas de íons inorgânicos dissolvidos, monômeros resinosos não polimerizados solúveis em água e componentes do colágeno dissolvidos na camada de inibição dos adesivos fotopolimerizáveis. Esta diferença de concentração pode estabelecer gradiente de pressão osmótica no local, promovendo movimento de água da região com menor concentração de soluto (túbulos dentinários) para a com maior concentração de soluto (camada de adesivo). A água que permeia a matriz resinosa pode acumular-se dentro de defeitos presentes nesta matriz, tais como bolhas de ar, promovendo a hidrólise e a liberação dos componentes da interface, levando à degradação da mesma.

Posteriormente, estes achados foram confirmados por outros estudos do mesmo grupo de pesquisa. Análises morfológicas da interface adesiva entre estes sistemas e a dentina, usando microscopia eletrônica de transmissão e dois agentes traçadores (nitrato de prata e nitrato de prata amoniacal), evidenciaram a presença de dois padrões distintos de infiltração na camada de adesivo, um reticulado em forma de "water-trees" ou árvores de água conectadas e outro em forma de grãos isolados de prata $^{19,20}$.

Os dois padrões representam, respectivamente, a água da superfície dentinária que não foi removida adequadamente no momento da aplicação do adesivo ou aquela que vem incorporada à composição de determinados sistemas e a fase hidrofílica da matriz de adesivo que absorve água. Tay et al. ${ }^{19}$ demonstraram posteriormente, em estudo clássico, que este fenômeno sofreu modificações significativas durante o período de 12 meses de armazenamento em água, o padrão reticulado de deposição dos grãos de prata diminuiu no corpo da camada híbrida e aumentou na interface entre esta e a camada de adesivo; já os depósitos pontuais de prata aumentaram em tamanho e densidade na camada de adesivo, até a formação de "watertrees". Os autores atribuíram estas modificações na matriz de adesivo à absorção de água ao longo do tempo.

\section{METALOPROTEINASES (MMPs)}

A degradação da interface, como ressaltado, também acontece no componente dentinário da mesma. $\bigcirc$ condicionamento ácido, principalmente com o ácido fosfórico, expõe as fibrilas de colágeno e pode provocar algum grau de desnaturação, e o colágeno exposto é passível de deterioração ${ }^{21}$. Evidências "In vitro"22,23 e "In vivo" 22 da desintegração da rede de fibrilas de colágeno são encontradas na literatura. Hashimoto et al. ${ }^{23}$ observaram desarranjo da rede de colágeno, aumento dos espaços interfibrilares e diminuição da espessura das fibrilas de colágeno, após o armazenamento da dentina, previamente condicionada com ácido fosfórico, por um período de 500 dias em água.

Enzimas conhecidas como metaloproteinases endógenas (MMPs) estão presentes na matriz extracelular dos tecidos dos mamíferos, como por exemplo na dentina humana, e possuem intensa atividade metabólica de remodelação e degradação de vários tipos de colágeno ${ }^{24}$.

Sabe-se que este grupo de enzimas, zinco e cálcio dependentes são inativadas pela descida do $\mathrm{pH}$, isso quando o condicionador ácido é lavado da superfície ou quando os monômeros acídicos dos sistemas autocondicionantes são polimerizados, tal efeito inibitório deixa de existir ${ }^{25}$.

Além da ação da água, recentemente temse especulado um mecanismo de deterioração enzimática envolvido nesta degradação. Enzimas com atividade gelatinolítica (MMP-2 e MMP-9) e colagenolítica (MMP-1, -8, -13,-18) estão presentes na sua forma latente na matriz mineralizada de dentina $^{26}$. Elas também são encontradas na saliva e podem ser secretadas pelos odontoblastos ${ }^{27,28}$.

Sua função é ativada pelo baixo $\mathrm{pH}^{27}$ ou inibida pela ação de inibidores de metaloproteinases como o TIMP $-1^{28}$ (Tissue Inhibitors of Metalloproteinases Inibidores tissulares de metaloproteinases). Estudos recentes têm revelado a contribuição destas enzimas no processo da cárie ${ }^{31}$. As metaloproteinases presentes na saliva e na dentina são ativadas pelas subsequentes desmineralização e remineralização existentes durante o desenvolvimento das lesões cariosas, promovendo a destruição da matriz de colágeno dentinário e conseqüente progressão da cárie dentária ${ }^{32}$. $\bigcirc$ mesmo processo pode ocorrer na interface adesiva ${ }^{28}$. 
Nos últimos 10 anos, várias MMPs (metaloproteinases) e cisteína catepsinas têm sido identificadas. MMPs e catepsinas são pertencentes a duas famílias enzimáticas distintas e são expressas em nível do mRNA (RNA mensageiro) pelos odontoblastos de mamíferos.

As cisteína catepsina pertence à família $\mathrm{Cl}$ de enzimas semelhantes à papaína, estando presente e sendo específica de alguns fluidos tissulares. Muitas delas são ativadas em meio ácido como as MMPs, sendo uma delas, a endopeptidase CC-B das catepsinas, que é ativada em pH neutro. Recentes estudos têm demonstrado uma forte associação das MMPs com as cisteína catepsinas promovendo maior degradação da matriz dentinária cariada (sendo sua ação 10 vezes maior do que quando em dentina hígida). Assim, vários estudos têm quantificado os produtos de degradação mediados pelas MMPs e mediados pelas cisteína catepsinas no telopeptídeo terminal $C$ do colágeno. Pode-se, assim quantificar e qualificar a degradação causada por cada enzima separadamente, bem como utilizar inibidores específicos para bloquear a atividade das MMPs e das catepsinas ${ }^{28}$.

Diante desses problemas uma cadeia de eventos pode acontecer durante os procedimentos adesivos. O condicionamento ácido expõe as fibrilas de colágeno e libera as metaloproteinases. Após liberadas essas enzimas, como parte de uma família de proteínas cátion-dependentes, utilizariam-se do cálcio residual presente no meio ou mesmo aquele liberado pela porção mineralizada da dentina na base da zona desmineralizada para sua ativação, promovendo a destruição das fibrilas de colágeno não impregnadas por resina. Ainda, alguma contribuição destas enzimas e do cálcio presentes na saliva pode ser esperada, principalmente naquelas situações clínicas em que as margens cavitárias situam-se em dentina ou em cemento. Em um estudo, Pashley et al. ${ }^{8}$ avaliaram a estabilidade da matriz dentinária de colágeno exposta pelo condicionamento com ácido fosfórico e armazenada em saliva artificial, com ou sem a presença dos inibidores proteolíticos, e em óleo mineral, por período máximo de 250 dias. Os autores observaram com este estudo que no grupo em que apenas a saliva artificial foi empregada como meio de armazenamento, foi observada perda parcial ou total da matriz dentinária de colágeno. Os autores ressaltam que não foram observadas bactérias nos espécimes e na saliva artificial utilizada. Ainda, segundo os autores, o que provavelmente ocorreu foi que as enzimas endógenas presentes na dentina foram ativadas pelo condicionamento ácido, sendo liberadas lentamente durante a incubação em solução aquosa, contribuindo assim para a degradação da rede de colágeno ${ }^{33}$. Moraes et al. ${ }^{34}$, em recente estudo, demonstraram que a dentina desmineralizada com concentrações de ácido fosfórico a 1\%, 10\% e 37\%, liberou mais íons cálcio conforme o aumento da concentração ácida. Contudo, a expressão e atividade de enzimas endógenas extraídas pela ativação da MMP-2 foi significativamente maior para a concentração de $10 \%$ de ácido fosfórico. Isso sugere que a diminuição do $\mathrm{pH}$ local, mesmo que produzido por um produto de baixa concentração, pode ativar as MMPs. Assim, a atividade dessas enzimas pode ser feita de uma maneira dose-dependente e deve ser pontualmente descoberta. Este estudo parece contradizer outros trabalhos que demonstraram a estabilidade da matriz desmineralizada em EDTA (ácido etileno diamino tetracético) pelo período de 48 meses $^{8,35}$. Esta divergência pode estar ligada ao tipo de ácido empregado, pois o EDTA reconhecidamente inibe a ação das metaloproteinases ${ }^{36}$.

\section{DESSENSIBILIZANTES}

Diante deste cenário, é fundamental a busca de soluções para o problema da degradação da interface adesiva. A água sem dúvida é a maior responsável por esta degradação, portanto, técnicas adesivas que permitam condições não tão críticas de umidade superficial e materiais adesivos que absorvam menos água serão fundamentais no futuro para se alcançar uma maior estabilidade da união. Além disso, produtos capazes de inibir a ação das enzimas humanas deveriam ser usados. Tentativas têm sido propostas na literatura consultada, tais como: cloreto de benzalcônio ${ }^{37,38}$, modificação da composição e uso de diferentes monômeros ${ }^{39,40}$, uso do etanol a $100 \%$ para eliminar o excesso de água e evitar a separação de fase dos monômeros ${ }^{28}$ dando tempo para infiltração uniforme, entre outros. Uma alternativa seria $\circ$ uso de dessensibilizantes dentinários. Pashley et al. ${ }^{5}$, observaram que a aplicação de um gel de oxalato de potássio sobre a dentina condicionada, previamente à aplicação de um sistema adesivo, bloqueou a permeabilidade dentinária, além de não interferir nos valores de 
resistência adesiva encontrados para um adesivo de frasco único. Tay et al. $^{20}$ mostraram que alguns produtos à base de oxalato, aplicados após - condicionamento ácido, não interferiram na resistência à microtração da resina composta à dentina e promoveram a formação de interfaces morfologicamente mais homogêneas, sem a presença das "water-trees". As soluções de ácido oxálico ou de oxalato de potássio acidificada atacam as áreas de dentina intertubular e a peritubular mineralizadas, logo abaixo da zona desmineralizada, formando cristais insolúveis de oxalato de cálcio que diminuem a transudação de fluido dentinário e limitam o movimento de água durante $\bigcirc$ procedimento adesivo ${ }^{28,41}$. Quando aplicados antes do condicionamento ácido, estes materiais podem interferir na adesão ${ }^{28}$, porém, se aplicados após o condicionamento ácido, isto não ocorre porque os cristais não se formam na superfície, já que não há cálcio na região para isso ${ }^{28}$.

Baseado nisto, a utilização de dessensibilizantes à base destes elementos poderia aumentar a durabilidade da união, já que promoveria melhor controle da umidade durante os procedimentos adesivos, em particular quando a técnica de condicionamento ácido total é empregada. Ainda, a ação quelante destes dessensibilizantes ${ }^{42}$ poderia, hipoteticamente, tornar indisponíveis os íons cálcio na região, inviabilizando a ação das metaloproteinases.

\section{ANTIMICROBIANOS}

Quando os sistemas adesivos autocondicionantes são utilizados, a hibridização ocorre sem que ocorra a remoção da smear layer, que permanece incorporada na camada híbrida. Assim, surgiu a hipótese da presença de bactérias remanescentes; e, pior, quiescentes nessa região, com proposta atual da incorporação de antimicrobianos nos adesivos. $O$ digluconato de clorexidina é uma bisguanidina com propriedades catiônicas. É estável, bactericida (morte bacteriana) em altas concentrações e bacteriostática (inibe o metabolismo bacteriano) quando em baixas concentrações. Possui substantividade e fixa-se à estrutura dentária por intermédio de íons positivos que se ligam a grupos fosfato do esmalte e dentina. Este antimicrobiano apresenta largo espectro de ação ${ }^{43,44,45}$ e tem sido utilizado como desinfetante cavitário durante os procedimentos adesivos, sem interferir no processo da adesão, mesmo quando aplicado após o condicionamento ácido ${ }^{45,46}$. A clorexidina é facilmente absorvida devido à sua atividade catiônica, rompendo as paredes bacterianas carregadas negativamente. Espécies como $\circ$ S. mutans e S. sobrinus, responsabilizados pela atividade inicial do processo carioso, são extremamente sensíveis a essa bisguanidina. A despeito de sua ação bactericida, Gendron et al. ${ }^{24}$ verificaram que a clorexidina tem capacidade para inativar as MMP-2, -8 e-9. A concentração de 0,03\% inibiu tanto a MMP-2 quanto a MMP-9, sendo que a MMP-2 foi a mais sensível. A MMP-8 foi inibida em concentrações baixas como $0,01 \%$ (devido à interação da clorexidina com os grupos sulfidrilo essenciais e/ou com a cisteína dos locais ativos no caso da MMP-8). O certo é que a clorexidina inibe proteases tanto em meio aquoso quanto ácido. Os autores ressaltam que um mecanismo de inibição por quelação do cálcio pode estar envolvido na inativação destas enzimas. A clorexidina tem sido sugerida em diferentes passos clínicos: antes do condicionamento ácido, depois do condicionamento ácido, incluído no condicionamento ácido, incluído no adesivo; a fim de, aumentar a longevidade de união adesiva; sem, contudo, aumentar o número de etapas no protocolo clínico.

\section{NOVOS MONÔMEROS}

OMDPB é um monômero formado pela união do grupo metacrilato tradicional com uma amônia quaternária, - brometo de metacriloiloxidodecilpiridínio, com efeito antibacteriano de largo espectro e capacidade de copolimerizar com outros monômeros. Sua forte ação antibacteriana é devida ao ingresso da amônia quaternária, tendo assim agentes catiônicos ativos na sua superfície ${ }^{3}$. Possui grupos hidrofílicos e hidrofóbicos que fazem interações iônicas. Promove ligações catiônicas com os grupos fosfato do ácido teicoico e polissacarídeos presentes na membrana celular bacteriana. Tal fato demonstra efetiva inibição no desenvolvimento de biofilme (bactericida inicialmente e bacteriostática ao longo do tempo) $)^{3}$. Aumenta-se também a hidrofilia, estabilidade da interface adesiva, eficácia de união, grau de conversão, adaptação marginal, biocompatibilidade e longevidade. O MDPB é mais viscoso do que o HEMA (2 hidroxi-etil-metacrilato) - que gera uma dificuldade maior de penetração nas anfractuosidades da dentina desmineralizada. O monômero DMAE-CB é semelhante ao anterior ${ }^{3}$, sendo bactericida inicialmente e bacteriostático por 
contato em fases posteriores de uso. Todavia, vale ressaltar que a confiabilidade biológica de tais monômeros não foi suficientemente testada para uso seguro em humanos e maiores pesquisas são necessárias.

\section{SOLVENTES}

Os solventes têm a função de conduzir os monômeros na matriz dentinária desmineralizada, com consequente expansão dos espaços interfibrilares. Para isso, têm a função de prevenir ligações com as moléculas de água através de pontes de hidrogênio interpeptídeos. Assim os solventes empregados para adesão têm a função de quebrar ligações iônicas, dispersivas e polares entre os peptídeos da matriz de colágeno quando em colapso. $O$ que determina a efetividade da quebra dessas ligações são os valores dos parâmetros de solubilidade. A velocidade de evaporação é determinada por uma propriedade chamada pressão de vapor ${ }^{6}$. Quanto maior a pressão de vapor, maior a velocidade de evaporação e mais voláteis têm de ser os solventes. Assim o solvente é capaz de deslocar mais água presente entre as fibrilas de colágeno.

Quanto maior a pressão de vapor do solvente maior a umidade na dentina para se promover a adesão. Os adesivos com solventes à base de água necessitam de mais tempo para evaporar, pois a água tem uma pressão de vapor menor do que o etanol e muito menor do que a acetona. $\mathrm{Se}$ a evaporação dos solventes for deficitária, isso compromete a diluição dos monômeros, com polimerização alterada e separação de fases dos componentes do adesivo. Também, solvente residual compromete a polimerização do sistema adesivo, - que favorece a transição de fluidos através da camada adesivab. Modernamente, um tipo de solvente alcoólico (t-butanol) foi incorporado a um sistema adesivo comercial de dois passos. $O$ t-butanol é um dos quatro isômeros do butanol, sendo muito solúvel em água e etanol. Tal solvente apresenta melhor estabilidade quando reage com os monômeros adesivos. O t-butanol é compatível com dentina seca, tem maior peso molecular, maior compatibilidade com a água e com monômeros ${ }^{47}$, mantém a mesma taxa de evaporação do etanol ${ }^{48}$, permite maior espessura de película do adesivo quando comparado com o solvente à base de acetona, tem excelente estabilidade química e boa capacidade de evaporação. Entretanto, na literatura consultada, encontrou-se contradição quanto aos autores que preferem adesivos com solventes à base de água por apresentarem eficiência de adesão em dentina seca ou úmida, pois os mesmos apresentam a capacidade de reumidificar e reexpandir as fibras colágenas parcialmente colapsadas após condicionamento ácido e secagem, o que permite permeação do adesivo na profundidade equivalente à desmineralização dentinária, tendo ainda, a vantagem de não ser tão crítico quanto à padronização por parte dos procedimentos clínicos executados pelos dentistas ${ }^{49}$. Fato curioso é a mudança contínua e revezamento entre acetona, etanol e água mesmo entre o mesmo fabricante. Alguns fabricantes utilizavam acetona, etanol e água, em versões mais recentes, a acetona foi suprimida. Outros utilizam o Tert-butanol, sendo que em versões anteriores do mesmo produto usavam a acetona como padrão. O Tert-butanol tem maior peso molecular, maior compatibilidade química com a água e monômeros, dá maior estabilidade e mantém a mesma taxa de evaporação do etanol, com maior espessura de película quando comparado com a versão que usava acetona.

\section{PERSPECTIVAS FUTURAS}

A bioengenharia molecular pode contribuir sobremaneira para $\circ$ desenvolvimento futuro de adesivos bioestáveis em concordância com a química de polímeros ${ }^{50}$. Com os avanços em nível molecular, na ciência de biomimética, monômeros serão derivados de bioadesivos secretados por animais aquáticos, que não dependem da energia de superfície do substrato e são menos sensíveis à degradação hidrolítica. São prioritariamente baseados em aminoácidos que estabelecem ligações cruzadas mais efetivas por reações enzimáticas, criandose bioadesivos proteicos estáveis e resistentes ${ }^{50}$. Moléculas com desdobramentos reversíveis, possuindo resiliência e tenacidade, absorvendo a tensão na interface adesiva, compensando-se a contração de polimerização e as cargas mastigatórias. Poderiam se regenerar, bem como liberar proteínas que restituíssem a matriz colagenosa alterada pela cárie, induzindo a formação de dentina reparadora ${ }^{50}$. Apesar de suposições, tais expectativas demandam um progresso constante em grandes centros de pesquisa. Afinal, a odontologia adesiva tem sido o foco de um grandioso número de pesquisas ao redor de todo o mundo. 


\section{CONCLUSÕES}

Pelo exposto, depreende-se que a utilização do dessensibilizante, a base de oxalato, e do desinfetante, a base de clorexidina, podem conferir maior estabilidade à união adesiva. Devido às limitações inerentes aos polímeros que formam a interface entre resina e dentina, provavelmente, a utilização destes materiais não solucionaria todos os problemas relativos à longevidade da mesma. Porém, caso tenham sua eficiência consagrada, os mesmos têm a possibilidade de ser largamente empregados, pois são de baixo custo, fácil acesso e aplicação. Mais estudos verificando tanto o efeito do oxalato quanto o da clorexidina na longevidade da união devem então ser realizados, no intuito de confirmar ou não os trabalhos aqui referenciados.

\section{REFERÊNCIAS}

1. Anchieta RB, Machado LS, Sundfeld RH, Reis AF, Giannini $M$, Luersen $M A$, et al. Effect of partially demineralized dentin beneath the hybrid layer on dentin-adhesive interface micromechanics. J. Biomechanics. 2015;48(4):701-7

2. Sano H, Yoshikawa T, Pereira PN, Kanemura N, Morigami M, Tagami J et al. Long-term durability of dentin bonds made with a self-etching primer, in vivo. J. Dent. Res. 1999;78(4):906-911

3. Martins DO, Vasconcelos MR, Portela AIP. Agentes antimicrobianos nos sistemas adesivos. Rev. Bras. Odontol. 2014;71(2):130-4

4. Rios LFFF, Calabria MP, Casas-Apayco LG, Honorio HM, Carrilho MR, Pereira JC et al. Chlorhexidine does not improve but preserves bond strength to eroded dentin. Am. J. Dent. 2015; 28(2):28-32

5. Pashley DH, Carvalho RM, Pereira JC, Villanueva $R$, Tay FR. The use of oxalate to reduce dentin permeability under adhesive restorations. Am. J. Dent. $2001 ; 14(2): 89-94$

6. Sousa JHP, Moro AFV. Solventes do primer: revisão de literatura. Rev. Bras. Odontol. 2014;71(1):80-4
7. Buonocore MG. A simple method of increasing the adhesion of acrylic filling materials to enamel surfaces. J. Dent. Res. 1955;34(6):849-53

8. Pashley DH, Tay FR, Yiu C, Hashimoto M, Breschi L, Carvalho RM. Collagen degradation by host-derived enzymes during aging. J. Dent. Res. 2004;83(3):21621

9. Loguercio AD, Muñoz MA, Luque-Martinez I, Hass V, Reis $A$, Perdigão J. Does active application of universal adhesives to enamel in self-etch mode improve their performance? J. Dent. 2015;43(9):1060-70

10. Ryou H, Turco G, Breschi L, Tay FR, Pashley DH, Arola D. On the stiffness of demineralized dentin matrices. Dent. Mater. 2016;32(2):161-70

11. Armstrong SR, Keller JC, Boyer DB. The influence of water storage and $c$-factor on the dentin-resin composite microtensile bond strength and debond pathway utilizing a filled and unfilled adhesive resin. Dent. Mater. $2001 ; 17(3): 268-276$

12. Agee KA, Prakki A, Abu-Haimed T, Naguib GH, Nawareg MA, Tezvergil-Mutluay $A$ et al. Water distribution in dentin matrices: bound vs. unbound water. Dent. Mater. 2015;31(3):205-16

\section{Eliades $G$, Vougiouklakis $G$, Palaghias $G$.} Heterogeneous distribution of single-bottle adhesive monomers in the resin-dentin interdiffusion zone. Dent. Mater. $2001 ; 17(4): 277-283$

14. Goes MF, Shinohara MS, Freitas MS. Performance of a new one-step multi-mode adhesive on etched vs. non-etched enamel on bond strength and interfacial morphology. J. Adhes. Dent. 2014;16(3):243-50

\section{Ayres AP, Tabchoury CPM, Berger SB, Yamauti} $M$, Ambrosano GMB, Giannini M. Effect of fluoridecontaining restorative materials on dentin adhesion and demineralization of hard tissues adjacent to restorations. J. Adhes. Dent. 2015;17(4):337-45

16. Munck J, Poitevin A, Lührs A, Pongprueksa P, Van Ende $A$, Van Landuyt KL et al. Interfacial fracture toughness of aged adhesive-dentin interfaces. Dent. Mater. 2015;31(4):462-72

17. Makishi P, André CB, Ayres APA, Martins AL, Giannini $M$. Effect of storage time on bond strength and nanoleakage expression of universal adhesives bonded to dentin and etched enamel. Oper. Dent. 
18. Tay FR, Pashley DH, Suh BI, Carvalho RM, Ittagharum A. Single-step adhesives are permeable membranes. J. Dent. Guildford. 2002;30(7-8):371 382

19. Tay FR, Hashimoto M, Pashley DH, Peters MC, Lai SC, Yiu CK et al. Aging affects two modes of nanoleakage expression in bonded dentin. J. Dent. Res. 2003;82(7):537-541

20. Tay FR, Pashley DH, Mak YF, Carvalho RM, Lai SC, Suh BI. Integrating oxalate desensitizers with total etch two-step adhesive. J. Dent. Res. 2003;82(9):703-707

21. Anchieta RB, Machado LS, Martini AP, Santos $\mathrm{PH}$, Giannini $M$, Janal $M$, et al. Effect of long-term storage on nanomechanical and morphological properties of dentin-adhesive interfaces. Dent. Mater. $2014 ; 31(3): 141-153$

22. Gunaydin Z, Yazici AR, Cehreli ZC. In Vivo and In Vitro effects of chlorhexidine pretreatment on immediate and aged dentin bond strengths. Oper. Dent. $2016 ; 41(3): 258-67$

23. Hashimoto $M$, Tay FR, Ohno $H$, Sano $H$, Kaga $M$, Yiu $C$ et al. SEM and TEM analysis of water degradation of human dentinal collagen. J Biomed Mater Res. 2003;66B(1):287-298

\section{Gendron R, Grenier D, Sorsa T, Mayrand}

$D$. Inhibition of the activities of matrix maetalloproteinases 2,8 , and 9 by chlorhexidine. Clin. Diag. Lab. Immun. 1999;6(3):437-39

25. Pamacóndor-Hernández C, Osorio R, Aguilera FS, Cabello I, Goes MF, Toledano M. Effect of zinc-doping in physicochemical properties of dental adhesives. Am. J. Dent. $2015 ; 28(5): 292-96$

26. André CB, Gomes BPFA, Duque TM, Stipp RN, Chan DC, Ambrosano GMB, et al. Dentine bond strength and antimicrobial activity evaluation of adhesive systems. J. Dent. 2015;43(4):466-75

27. Tezvergil-Mutluay A, Agee KA, Mazzoni A, Carvalho RM, Carrilho M, Tersariol IL et al. Can quaternary ammonium methacrylates inhibit matrix MMPs and cathepsins? Dent. Mater. 2014;31(2):e2532

28. Tezvergil-Mutluay A, Pashley DH, Mutluay MM. Long-term durability of dental adhesives. Curr. Oral
29. Pinto CF, Berger SB, Cavalli V, Russo AKB, Giannini $M$. Influence of chemical and natural cross-linkers on dentin bond strength of self-etching adhesives. Int. J. Adhes. and Adhesives. 2015;60(4):117-22

30. Pinto CF, Berger SB, Cavalli V, Cruz SE, Goncalves $R B, A m b r o s a n o ~ G M B$ et al. In situ antimicrobial activity and inhibition of secondary caries of self-etching adhesives containing an antibacterial agent and/or fluoride. Am. J. Dent. 2015;28(3):167-73

31. Tjäderhane L, Buzalaf MAR, Carrilho M, Chaussain C. Matrix metalloproteinases and other matrix proteinases in relation to cariology: The Era of dentin degradomics'. Caries Res. 2015;49(3):193-208

32. Zhou J, Chiba A, Scheffel DLS, Hebling J, Agee $K$, Niu $L$ et al. Effects of a dicalcium and tetracalcium phosphate-based desensitizer on in vitro dentin permeability. PLoS ONE. 2016; 11 (6):e0158400

33. Hass V, Martinez IL, Munoz MA, Gutierrez $M F$, Abuna $G$, Sinhoreti $M$ et al. The effect of proanthocyanidin-containing 10\% phosphoric acid on bonding properties and MMP inhibition. Dent. Mater. 2016;32(3):468-75

34. Moraes AGD, Francci C, Vidal CMP, Scaffa PMC, Nesadal D, Yamasaki LC et al. Phosphoric acid concentration effects dentinal MMPs activity. J. Dent. 2016.53:30-7

35. Pongprueksa P, De Munck J, Duca RC, Poels K, Covaci $A$, Hoet $P$ et al. Monomer elution in relation to degree of conversion for different types of composite. J. Dent. 2015;43(1 2):1448-55

36. Brackett MG, Agee KA, Brackett WW, Key WO, Sabatini C, Kato MT et al. Effect of sodium fluoride on the endogenous MMP activity of dentin matrices. J. Nat. Sci. 2015;1(6):e 118

37. Sabatini C, Pashley DH. Aging of adhesive interfaces treated with benzalkonium chloride and benzalkonium methacrylate. Eur. J. Oral Sci. $2015 ; 123(2): 102-7$

38. Sabatini C, Ortiz PA, Pashley DH. Preservation of resin-dentin interfaces treated with benzalkonium chloride adhesive blends. Eur. J. Oral Sci. 2015;123(2):108-15 
39. Miletic V, Pongprueksa P, Munck JD, Brooks NR, Van Meerbeek B. Monomer-to-polymer conversion and micro-tensile bond strength to dentine of experimental and commercial adhesives containing diphenyl (2,4,6-trimethylbenzoyl) phosphine oxide or a camphorquinone/amine photo-initiator system. J. Dent. 2013;41(10):918-26

40. Sabatini C, Mennito AS, Wolf BJ, Pashley DH, Renné WG. Incorporation of bactericidal poly-acrylic acid modified copper iodide particles into adhesive resins. J. Dent. 2015;43(5):546-55

41. Tian F, Wang X, Huang Q, Niu L, Mitchell J, Zhang $Z$ et al. Effect of nanolayering of calcium salts of phosphoric acid ester monomers on the durability of resin-dentin bonds. Acta Biomat. 2016;27(38):190200

42. Mine A, De Munck J, Cardoso MV, Van Landuyt $K L$, Poitevin A, Van Ende A et al. Dentin-smear remains at self-etch adhesive interface. Dent. Mater. $2014 ; 30(10): 1147-53$

43. Apolonio FM, Souza LC, Silva FCFAE, Yamauti M, Breschi L, Saboia VPA. Evaluation of resin/dentin bonded interfaces formed by different adhesive strategies and exposed to $\mathrm{NaOCl}$ challenge. Int. J. Adhes. and Adhesives. 2015;59(6):21-26

44. Garcia RN, Giannini M, Takagaki T, Sati T, Matsui $N$, Nikaido T, et al. Effect of dentin desensitizers on resin cement bond strengths. Rev. Sul-Bras. Odontol. 2015;12(1):14-22

45. Loguercio AD, Hass V, Reyes MFG, Luque-Martinez IV, Szesz A, Stanislawczuk R, et al. Five-year Effects of chlorhexidine on the in vitro durability of resin/dentin interfaces. J. Adhes. Dent. 2016;18(1):35-42

46. Nawareg MMA, Elkassas D, Zidan AZ, Abuelenain $D$, Haimed TA, Hassan AH et al. Is chlorhexidinemethacrylate as effective as chlorhexidine digluconate in preserving resin dentin interfaces? J. Dent.

$2016 ; 1(45): 7-13$

47. Aguiar TR, André CB, Correr-Sobrinho L, Arrais CAG, Ambrosano GMB, Giannini M. Effect of storage times and mechanical load cycling on dentin bond strength of conventional and self-adhesive resin luting cements. J. Prosthet. Dent. 2014;1 11 (5):404-410

48. Jee SE, Zhou J, Tan J, Breschi L, Tay FR, Grégoire

$G$ et al. Investigation of ethanol infiltration into demineralized dentin collagen fibrils using molecular dynamics simulations. Acta Biomater. 2016;8(36):17585

49. Zhang Z, Tian F, Niu L, Ochala K, Chen C, Fu $B$ et al. Defying ageing: An expectation for dentine bonding with universal adhesives? J. Dent. $2016 ; 30(45): 43-52$

50. Mondelli J. Fundamentos de Dentística Operatória. $1^{a}$ Reimpressão. São Paulo: Santos; 2014 